\title{
Fundamentals of materials (text readability evaluation)
}

\author{
Aleksander Kiselnikov ${ }^{1 *[0000-0003-2639-678 X],}$ Diliara Vakhitova ${ }^{10000-0002-8851-5521]}$, and Tatiana \\ Kazymova ${ }^{1}$ [0000-0002-7853-0461] \\ ${ }^{1}$ Kazan State University of Architecture and Engineering, 420043, Zelenaya st., Kazan, Russia
}

\begin{abstract}
Fundamentals of materials represent a core subject at engineering universities dealing with various construction materials. The study of the discipline and the acquiring of knowledge demand a properly designed manual. Apart from content, manual authors should pay attention to the way they compose the text. Different tools are applied to assess the quality of a manual (its difficulty, complexity, readability). Readability formulae play a significant role in the sphere. Dealing with quantitative parameters of a text (the length of sentences, the length of words and others), readability formulae are able to predict the level of text readability and relate the text to a potential reader in respect to their age and academic level. Flesch-Kincaid Readability Level formula is chosen to analyze two manuals: one comes in the English language, the other - in Russian. The idea is to check how readable the texts of both manuals are. 17 English and 17 Russian texts are taken for the analysis. Pearson correlation is applied to illustrate whether the manuals demonstrate decrease or increase of the readability level of texts throughout the books.
\end{abstract}

Keywords: Readability, text readability, readability formula, FleschKincaid Readability Level, fundamentals of materials.

\section{Introduction}

University education is considered to be of high importance for future specialists in different spheres. Engineering universities provide society with highly qualified specialists in the sphere. A set of subjects at such universities is quite the same in different countries. The academic process, set of disciplines, levels of education in Russia are normalized to the European standards of education [1]. The study of fundamentals of materials is a core discipline for any engineering specialty dealing with materials, their processing, usage, utilization etc. The success of text information comprehension depends on many factors related to the reader: background, interests, involvement, and age. They all are of high importance. The article is devoted to the study of the content of manuals, i.e. the texts and their readability level.

Text readability is evaluated due to quantitative parameters of a text [2]. Thus, no other factors except the ones that belong to the text itself influence the readability level. Different readability formulae suppose different metrics to process texts. However, we can point out

*Corresponding author: kalejandr@gmail.com 
the most significant parameters that occur in the most readability formulae: number of words per sentence, number of letters per word, number of syllables per word, number of words containing three or more syllables. The calculated readability level correlates to the years of a reader who is expected to have a certain level of academic qualification in accordance with the age.

To perform the analysis we address to the study of the texts of two manuals on the fundamentals of material: in English and Russian languages. The English manual is «Fundamentals of Materials Science and Engineering. An Integrated Approach» by William D. Callister, Jr. and David G. Rethwisch [3]. The Russian Manual is «Material Science» (Materailovedenie) by I.M. Zharskij, N.P. Ivanova, D.V. Kuis, N.A. Svidunovich [4].

The idea is to examine the distribution of texts throughout the manuals: the texts are to be of the same readability level. We do not expect any significant decrease or increase of readability indices as the manuals are designed as student books for engineering specialties. The information is expected to be acquired by native speakers - students of universities. Thus, both manuals can be compared.

In spite of, information is distributed differently throughout the manuals, the content of two manuals under the study is quite the same.

The analysis of the texts' readability is performed by means of automated tools. We should stress out that the tools are different. The reason is the absence of a unique tool that can process both English and Russian texts, which relate to the academic sphere.

In this research, we are guided by the two key questions:

1. How readable the texts in the English manual are.

2. How readable the texts in the Russian manual are.

Any academic process supposes contact of a student with information that is a source of knowledge. Students can acquire information in different ways: listening, reading, watching etc. The written/typed text is the most usual and traditional source of information. In the context of an academic discourse students deal with texts in different manuals and on the Internet. Any text potentially comes as a source of knowledge. The success of its comprehension depends not only on a reader but also on the text itself (lexis, grammar structures and others). A wrongly designed text can block all attempts of a reader to get new information.

The problem is topical nowadays. As a result, different digital tools are designed to simplify and unify the process of a proper text choice or creation. Among a wide range of tools devoted to the analysis of the text and its difficulty, complexity, and readability, in the present article we are concentrated on readability. There are some reasons. We are strongly interested in a text itself, excluding all factors related to readers, their background or experience. Thus, we have to exclude the text difficulty analysis as it primarily deals with the reader features.

The study of text complexity supposes a wide range of text parameters such as referential cohesion, lexical diversity, syntactic complexity, the presence of formulae etc. There are many automated tools for text complexity evaluation, like Coh-Metrix [5] and ReaderBench [6]. They are implemented in many research works [7-12].

As our research is aimed at a cross-language (English-Russian) analysis, we cannot implement these tools, because they are not able to operate with texts in the Russian language. However, apart from text complexity parameters, the tools suggest the idea of a readability level evaluation as an initial step of a text analysis. Readability level determination is the simplest way to understand whether the texts are proper or not for the audience.

The range of readability formulae is broad: Flesch Reading Ease, Flesch-Kincaid Readability Level, Gunning Fog Index, Coleman-Liau index, Dale-Chall readability 
Formula, SMOG Readability Formula and many others. They are designed for different languages, for the texts of different genres, for native speakers and second language learners [13-19]. As we suppose the cross-language (English-Russian) analysis of texts, we should implement the formula, which can be applied for both: English and Russian language texts. Thus, for the analysis we have chosen Flesch-Kincaid Grade level formula [20], as it is one of the most popular and trustworthy in academic society.

The original formula was designed in the middle of the previous century to deal with texts in English. Thus, the Russian language texts cannot be analyzed with the same variant of the formula due to a different language system. However, Russian linguists reinterpreted the formula, due to the performed analysis and calculations, and suggested variants for the analysis of texts in Russian. Among a variety of adopted formulae, we trust [21] as it was purposefully designed for the analysis of academic texts. Due to the fact that we deal with texts of manuals which are recommended for the educational purposes, this condition is significant.

Further, we demonstrate the difference between the original Flesch-Kincaid Grade level formula (FK) (Eq. 1) and its adopted variant (FKa) (Eq. 2):

$$
\begin{gathered}
\mathrm{FK}=(0.39 \times \mathrm{ASL})+(11.8 \times \mathrm{AWL})-15.59 \\
\mathrm{FKa}=(0.36 \times \mathrm{ASL})+(5.76 \times \mathrm{AWL})-11.97
\end{gathered}
$$

where,

ASL - average number of words per sentence;

AWL - average number of syllables per word

\section{Materials and methods}

Two manuals «Fundamentals of Materials Science and Engineering. An Integrated Approach» and «Material Science» (Materailovedenie) are the objects of our analysis. The content of the «Fundamentals of Materials Science and Engineering. An Integrated Approach» is comprised of 20 units. The content of the «Material Science» (Materailovedenie) consists of 17 units.

We randomly choose 17 English and 17 Russian text extracts from different units. The chosen texts should satisfy a set of terms:

1. The length of the text.

2. The absence of formulae.

The length of texts is measured in words. The average length is 350 words. Some variations are possible but within the limits of 330-370 words. This condition is essential to be sure that each text has its logical beginning and ending. We should note that no information is removed from the chosen texts.

As we deal with technical manuals, they usually contain a lot of formulae. However, the consideration of formulae presence - is the task of a text complexity evaluation, but not its readability.

The English texts are labeled E1-E17, the Russian texts - R1-R17, respectively. The higher the number is, the further the text from the beginning of the manual is.

The analysis is performed in four stages:

Stage 1. Each English text is analyzed on the automated computational platform [22].

Stage 2. Each Russian text is analyzed on the automated computational platform Rulingva [23].

Stage 3. The obtained readability indices of English and Russian texts are crossanalyzed. 
Stage 4. Pearson correlation coefficient formula is implemented to compute the strength and direction of a linear relationship between:

a) FK index and a text position in the English manual;

b) FKa index and a text position in the Russian manual.

\section{Results}

The performed analysis allows presenting the obtained results.

Firstly, we evaluate the readability indices of 17 English texts. Secondly, we evaluate the readability indices of 17 Russian texts.

Fig. 1 represents FK Grade level indices of English texts (E1-E17); Fig. 2 - FKa Grade level indices of Russian texts (T1-T17).

\section{FK}

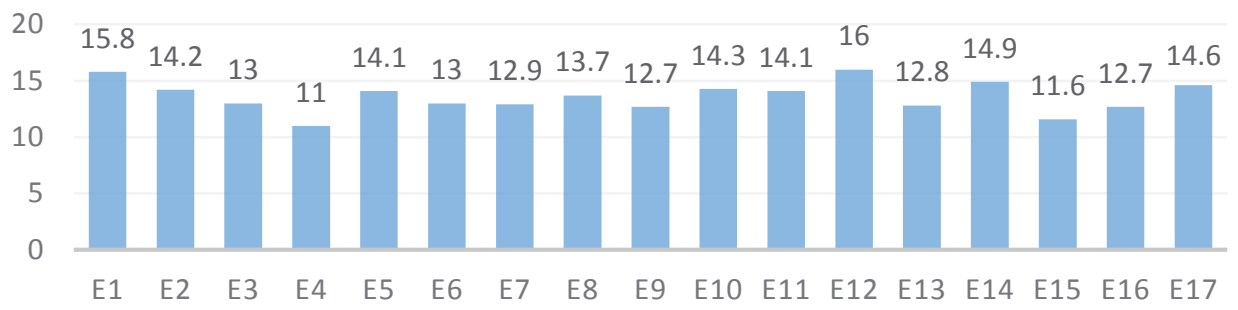

Fig. 1. FK Grade Level indices (English texts).

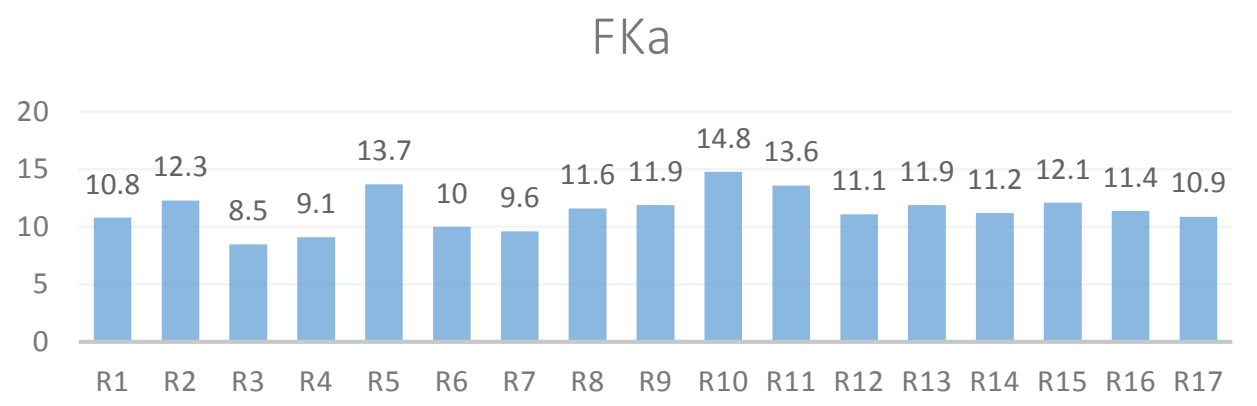

Fig. 2. FKa Grade Level indices (Russian texts).

Fig. 1 demonstrates the range of FK readability indices for 17 English texts. The higher the index is the more readable the text is. Although the texts demonstrate rather different level of readability - the indices are within the limits of 11 and $16-$, they cover the target audience - college or university students. Due to the table of readability indices, the texts are expected to be read by 18-23 year old people. Any significant change of indices throughout the manual is not detected.

Fig. 2 demonstrates the range of FKa readability indices for 17 Russian texts. The higher the index is the more readable the text is. Readability indices demonstrate that all analyzed texts are within the limits of 8.5 and 14.8. Thus, they are expected to be read by 15-22 year old people. This age covers the students of high school, colleges and universities. Primarily, this is the target audience of the manual. No significant decrease or increase of readability of texts is detected. Comparing to the English texts, the Russian ones demonstrate a wide spectrum of indices. As a result, they are less normalized. 


\section{Discussion}

The 17 English and 17 Russian analyzed texts reflect the readability level of the manuals under examination. Each text for the analysis is a part of a new unit of the manual. As we have selected 17 texts from each manual, we have covered all units of the Russian manual and almost the entire English manual.

Thus, due to the detected readability level indices we can claim that both manuals satisfy the age condition of a predicted target group - the students of universities.

To support the idea that texts do not significantly increase or decrease their readability level throughout the manuals we applied Pearson correlation.

Each text is marked with a number which demonstrates it remoteness from the beginning of the manual i.e. texts E1 and T1 are in the beginning, while texts E17 and T17 are in the end of the manuals.

Pearson correlation coefficient $(r)$ between English texts' remoteness from the beginning of the book and their FK indices is $r=-0.020268037$. The absence of correlation is obvious. Texts are written in the same manner and the position of a text in the manual does not influence its readability.

Pearson correlation coefficient $(r)$ between Russian texts' remoteness from the beginning of the book and their FKa indices is $r=0.25551925$. The correlation is not detected. However, comparing to English texts, the Russian ones are not so alike.

\section{Conclusions}

The research demonstrates the implementation of Flesch-Kincaid Grade level Readability formula for the analysis of 34 texts that come from two manuals in English and Russian languages on the topic of «Fundamentals of materials».

The analysis clearly illustrates that both manuals are balanced in the terms of text readability indices.

The English manual demonstrates a strong correlation with the target audience students of the university. This conclusion is possible due to the got results, which clearly point out the age of a reader 18-23.

The Russian manual is less balanced. Nevertheless, it demonstrates relatively close information on the readability level of the texts. They are supposed to be read by 15-22 year old people.

In future, we plan to implement other tools for the text analysis. It would be of interest to evaluate the complexity of texts. However, this task is a long-term goal as there are tools for the English language texts complexity analysis and no tools for the Russian language texts analysis.

\section{References}

1. M. I. Solnyshkina, E. N. Solovova, E. V. Harkova, A. S. Kiselnikov, Language Assessment course: Structure, Delivery and Learning Outcomes, International Journal of Environmental \& Science Education 11, 6, 1223-1229 (2016) DOI: 10.12973/ijese.2016.392a

2. M. I. Solnyshkina, A. S. Kiselnikov, Text complexity: Study phases in Russian linguistics, in Vestnik Tomskogo Gosudarstvennogo Universiteta, Filologiya 6, 38, 8699 (2015) DOI: 10.17223/19986645/38/7

3. W. D. Callister, Jr. and D. G. Rethwisch, Fundamentals of Materials Science and Engineering, An Integrated Approach, $5^{\text {th }}$ ed. 2015. 
4. I. M. Zharskij, N. P. Ivanova, D. V. Kuis, N. A. Svidunovich, Material Science (Materailovedenie) (2015)

5. D. S. McNamara, A. C. Graesser, P. M. McCarthy, Z. Cai, Automated evaluation of text and discourse with Coh-Metrix, (Cambridge University Press, Cambridge, 2014)

6. M. Dascalu, G. Gutu, S. Ruseti, I. C. Paraschiv, P. Dessus, D. S. McNamara, S. A. Crossley, S. Trausan-Matu, ReaderBench: A Multi-lingual Framework for Analyzing Text Complexity, EC-TEL, $495-499$ (2017)

7. S. Latifi, M. Gierl, Automated scoring of junior and senior high essays using CohMetrix features: Implications for large-scale language testing, Language Testing, 38, 1, 62-85 (2021) DOI:10.1177/0265532220929918

8. Y. Chang, D. Stone, Why does decomposed audit proposal readability differ by audit firm size? A Coh-Metrix approach, Managerial Auditing Journal 34, 8, 895-923 (2019). DOI: 10.1108/MAJ-02-2018-1789

9. S. A. Crossley, K. Kyle, Assessing writing with the tool for the automatic analysis of lexical sophistication (TAALES). Assessing Writing 38, 46-50 (2018) DOI: 10.1016/j.asw.2018.06.004

10. V. C. Yuah, S. Dongkwang, E. K. Go, Comparing L2 learners' writing against parallel machine-translated texts: Raters' assessment, linguistic complexity and errors, System, 96 (2021) DOI: 10.1016/j.system.2020.102408.

11. C. MacArthur, A. Jennings, Z. Philippakos, Which linguistic features predict quality of argumentative writing for college basic writers, and how do those features change with instruction? Reading and Writing 32, 6, 1553-1574 (2019) DOI: 10.1007/s11145-0189853-6

12. V. S. Cioaca, M. Dascalu, D. S. McNamara, Extractive Summarization using Cohesion Network Analysis and Submodular Set Functions 22nd International Symposium on Symbolic and Numeric Algorithms for Scientific Computing (SYNASC), 161-168 (2020) DOI: 10.1109/SYNASC51798.2020.00035

13. C. Polio, H. Yoon, The reliability and validity of automated tools for examining variation in syntactic complexity across genres, International Journal of Applied Linguistics (United Kingdom), 28, 1, 165-188 (2018) DOI: 10.1111/ijal.12200

14. S. Crossley, S. Skalicky, M. Dascalu, D. McNamara, K. Kyle, Predicting Text Comprehension, Processing, and Familiarity in Adult Readers: New Approaches to Readability Formulas. Discourse Processes, 54, 5-6, 340-359 (2017) DOI: 10.1080/0163853X.2017.1296264

15. S. Valizadeh-Haghi, Y. Khazaal, S. Rahmatizadeh, Health websites on COVID-19: are they readable and credible enough to help public self-car, Journal of the Medical Library Association, 109(1), 75-83 (2021) DOI: 10.5195/jmla.2021.1020

16. R. I. Zraick, M. Azios, M. M. Handley, M. L. Bellon-Harn, V. Manchaiah, Quality and readability of internet information about stuttering, Journal of Fluency Disorders, 67 (2021) DOI: 10.1016/j.jfludis.2020.105824

17. E. M. Grose, C. P. Holmes, K. A. Aravinthan, et al., Readability and quality assessment of internet-based patient education materials related to nasal septoplasty, J of Otolaryngol - Head \& Neck Surg , 50(16) (2021) DOI: 10.1186/s40463-021-00507-z

18. A. Vincze, N. H. Baranyai, H. Zsiborács, S. Csányi, I. Háber, G. Pintér, Communicating Renewable Energy in the National Action Plans of the Member States of the European Union, Sustainability, 12, 970 (2020) DOI: 10.3390/su12030970

19. A. Crossley, D. McNamara, Text readability and intuitive simplification. A comparison of readability formulas, Reading in a Foreign Language 23, 1, 84-101 (2011)

20. J. P. Kincaid, R. P. Fishburne, R. L. Rogers, B. S. Chissom, Derivation of new readability formulas (Automated Readability Index, Fog Count and Flesch Reading 
Ease Formula) for navy enlisted personnel. Naval technical training command, (Memphis, TN: Naval Air Station, 1975)

21. V. Solovyev, V. Ivanov, M. Solnyshkina, Assessment of Reading Difficulty Levels in Russian Academic Texts: Approaches and Metrics, Journal of Intelligent and Fuzzy Systems, 3049-3058 (2018) DOI:10.3233/JIFS-169489

22. Readability test tool, https://www.webfx.com/tools/read-able/check.php, last accessed 2021/04/16

23. RuLingva, https://rulingva.kpfu.ru/, last accessed 2021/04/16 